\title{
TOKM Hardware Operation Manual
}

\section{UNITED STATES PROGRAM \\ FOR TECHNICAL ASSISTANCE TO LAEA SAFEGUARDS}

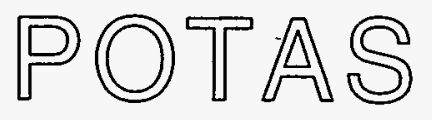

DEPARTMENT OF STATE

DEPARTMENT OF ENERG

ARMS CONTROL AND DISARMAMENT AGENCY NUCLEAR REGULATORY COMMISSION

\section{Los Alamos \\ NATIONAL LABORATORY}

Los Alamos National Laboratory is operated by the University of California for the United States Department of Energy under contract W-7405-ENG-36. 
Edited by Paul W. Henriksen, Group CIC-1

Prepared by Celina M. Ortiz, Group NIS-5

This work was supported by the U.S. Department of Energy, Office of Nonproliferation and National Security, International Safeguards Division, and Program for Technical Assistance to IAEA Safeguards.

An Affirmative Action/Equal Opportunity Employer

This report was prepared as an account of work sponsored by an agency of the United States Government. Neither The Regents of the University of California, the United States Government nor any agency thereof, nor any of their employees, makes any warranty, express or implied, or assumes any legal liability or responsibility for the accuracy, completeness, or usefulness of any information, apparatus, product, or process disclosed, or represents that its use would not infringe privately owned rights. Reference herein to any specific commercial product, process, or service by trade name, trademark, manufacturer, or otherwise, does not necessarily constitute or imply its endorsement, recommendation, or favoring by The Regents of the University of California, the United States Government, or any agency thereof. The views and opinions of authors expressed herein do not necessarily state or reflect those of The Regents of the University of Califormia, the United States Government, or any agency thereof. 


\section{DISCLAIMER}

Portions of this document may be illegible in electronic image products. Images are produced from the best available original document. 


\title{
TOKM Hardware Operation Manual
}

\author{
H. O. Menlove \\ J. K. Halbig \\ S. F. Klosterbuer \\ G. E. Bosler \\ R. Abedin-Zadeh* \\ B. Syed-Azmi*
}

\section{DISCLAIMER}

This report was prepared as an account of work sponsored by an agency of the United States Government. Neither the United States Government nor any agency thereof, nor any of their employees, makes any warranty, express or implied, or assumes any legal liability or responsibility for the accuracy, completeness, or usefulness of any information, apparatus, product, or process disclosed, or represents that its use would not infringe privately owned rights. Reference herein to any specific commercial product, process, or service by trade name, trademark, manufacturer, or otherwise does not necessarily constitute or imply its endorsement, recommendation, or favoring by the United States Government or any agency thereof. The views and opinions of authors expressed herein do not necessarily state or reflect those of the United States Government or any agency thereof.

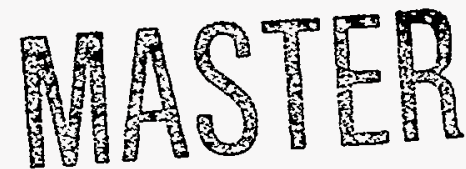





\section{CONTENTS}

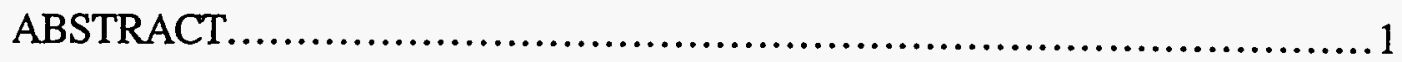

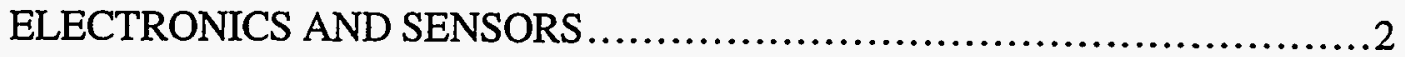

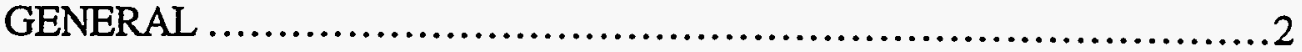

PHYSICAL DESCRIPTION............................................ 2

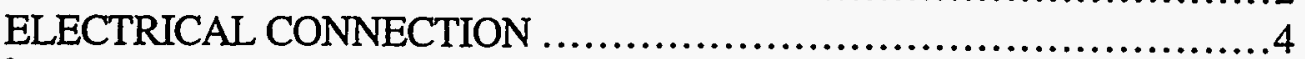

${ }^{3} \mathrm{He}-\mathrm{TUBE}$ HIGH-VOLTAGE PLATEAU.............................6

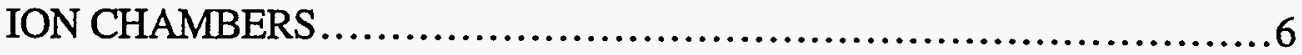

INSTALLATION.............................................................

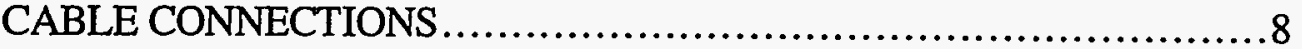

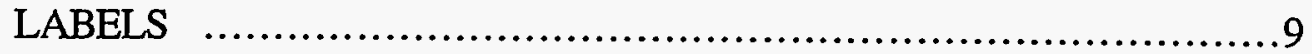

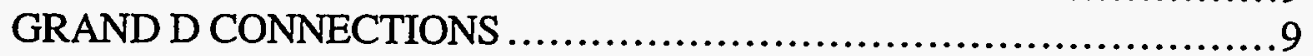

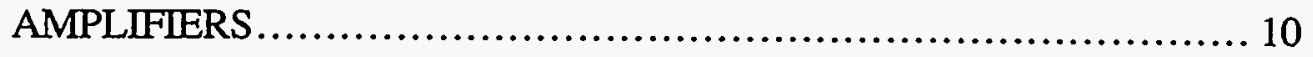

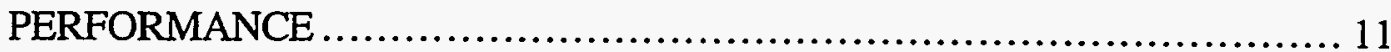

PERFORMANCE CHARACTERISTICS............................... 11

${ }^{3} \mathrm{He}$ TUBE TESTS ....................................................... 11

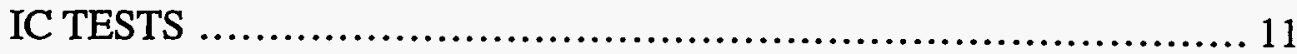

CALIBRATION .................................................. 13

CALIBRATION ............................................................ 15

NORMAL CHUTE RESULTS .......................................... 15

BY-PASS CHUTE RESULTS ...................................... 15

REVERSE DIRECTION TRANSFER.............................. 15

MAINTENANCE AND SAFETY........................................... 21

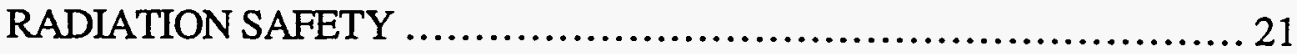

ELECTRICAL CABINET ............................................. 21

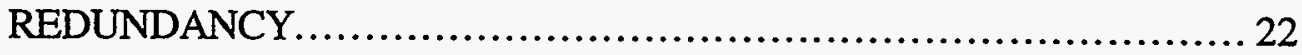

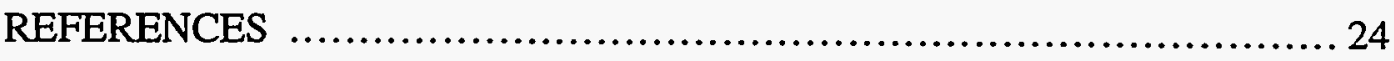




\title{
TOKM HARDWARE OPERATION MANUAL
}

\author{
by
}

H. O. Menlove, J. K. Halbig, S. F. Klosterbuer, G. E. Bosler, R. Abedin-Zadeh, and B. Syed-Azmi

\begin{abstract}
This manual describes the detector design features, performance, and operating characteristics of the Tokai-1 spent fuel monitor. The system includes a pair of monitors- - one for the primary (normal) fuel transfer chute and one for the by-pass fuel transfer chute. Each monitor contains four independent detector tubes to provide direction of travel and redundancy. There are two ion chambers and two ${ }^{3} \mathrm{He}$ tubes inside each detector package. All of the detectors are used to monitor the presence of spent-fuel gamma rays as the fuel rods pass alongside the detector package. Gamma-ray and neutron detector (GRAND) electronics supply power to the ion chambers and ${ }^{3} \mathrm{He}$ tubes, and the data is collected in the GRAND and the Kontron computer. The system is designed to operate unattended with data pickup by the inspectors on a 90-day period. This manual gives the performance and calibration parameters.
\end{abstract}


GENERAL

PHYSICAL DESCRIPTION
This manual describes the design features and operating characteristics of the Tokai-1 monitor (TOKM) for spent-fuel discharge. The TOKM will be used by the International Atomic Energy Agency (IAEA) to verify the time and direction of all spent fuel discharged from the Tokai-1 reactor.

The IAEA prepared the user requirements for the TOKM system and Los Alamos prepared the specifications and design of the integrated system including the detector, electronics, computer, and software. The detector packages were installed on the fuel discharge chutes by the IAEA in July 1994. The follow-up installation and calibration of the electronics and computers was in October 1994.

The TOKM system includes the following components:

- detector package (2 each)

2 ion chambers (ICs)

$2{ }^{3} \mathrm{He}$ tubes

2 AMPTEK amplifiers

1 remote disconnect relay

- electronics cabinet (IAEA)

- Grand-3 (2 each)

- Kontron IP lite (2 each)

- Bernoulli (2 each)

$P C$ powered

- Bernoulli (2 each)

Transportable

Figure 1 shows a diagram of a detector package including the ion chambers, ${ }^{3} \mathrm{He}$ tubes, and AMPTEK amplifier.' Figure 2 shows a photograph of the two units with the outer pipe removed. The detectors are set in a $\mathrm{CH}_{2}$ half-cylinder to fix their positions and to moderate the neutrons. The ${ }^{3} \mathrm{He}$ tubes have a thin lead shield ( $3 \mathrm{~mm}$ thick) to decrease the gamma dose, and the AMPTEK amplifier has a 6.4-mmthick tungsten shield for the same purpose. Figure 3 shows a closeup of the tungsten shield, an ion chamber, and a ${ }^{3} \mathrm{He}$ tube. 


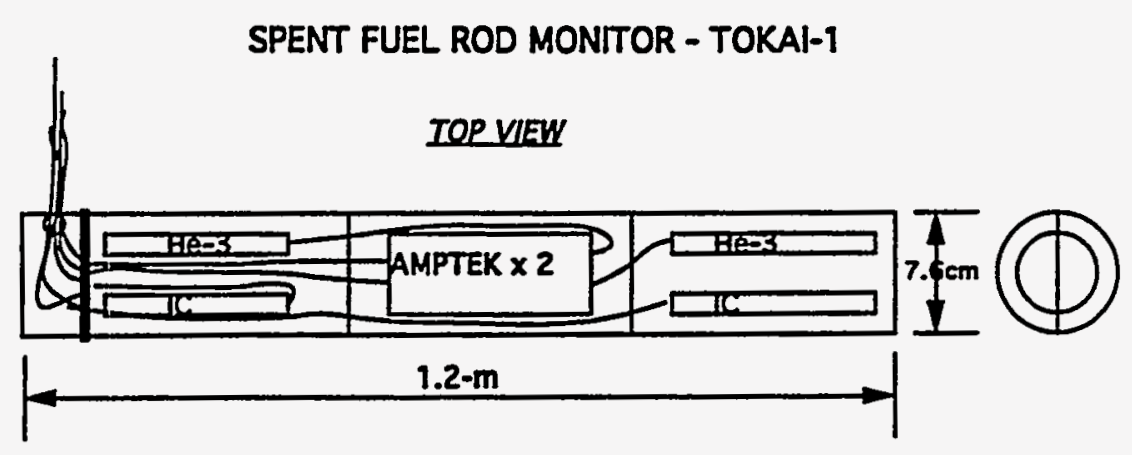

Fig. 1. Schematic diagram of the TOKM detector package including two ${ }^{3} \mathrm{He}$ tubes, two

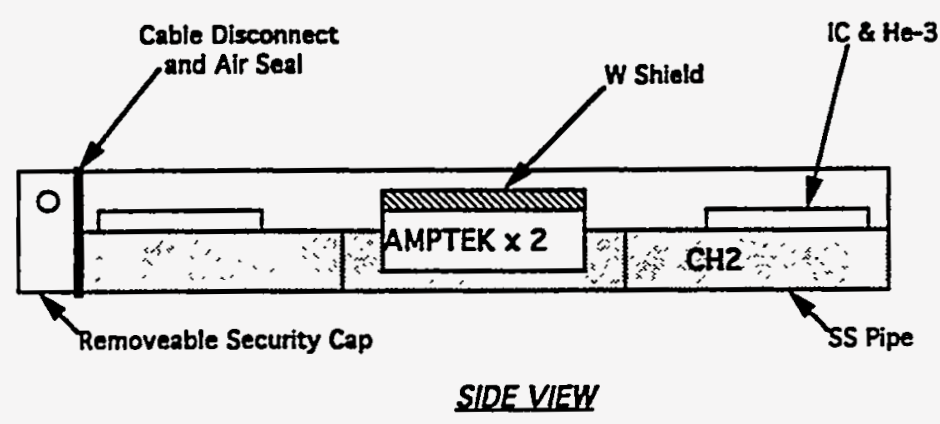
ICs, and a dual-channel AMPTEK amplifier for the ${ }^{3} \mathrm{He}$ tubes.

Fig. 2. Photograph of the two TOKM detector packages with the polyethylene inserts removed from the stainless steel pipes.

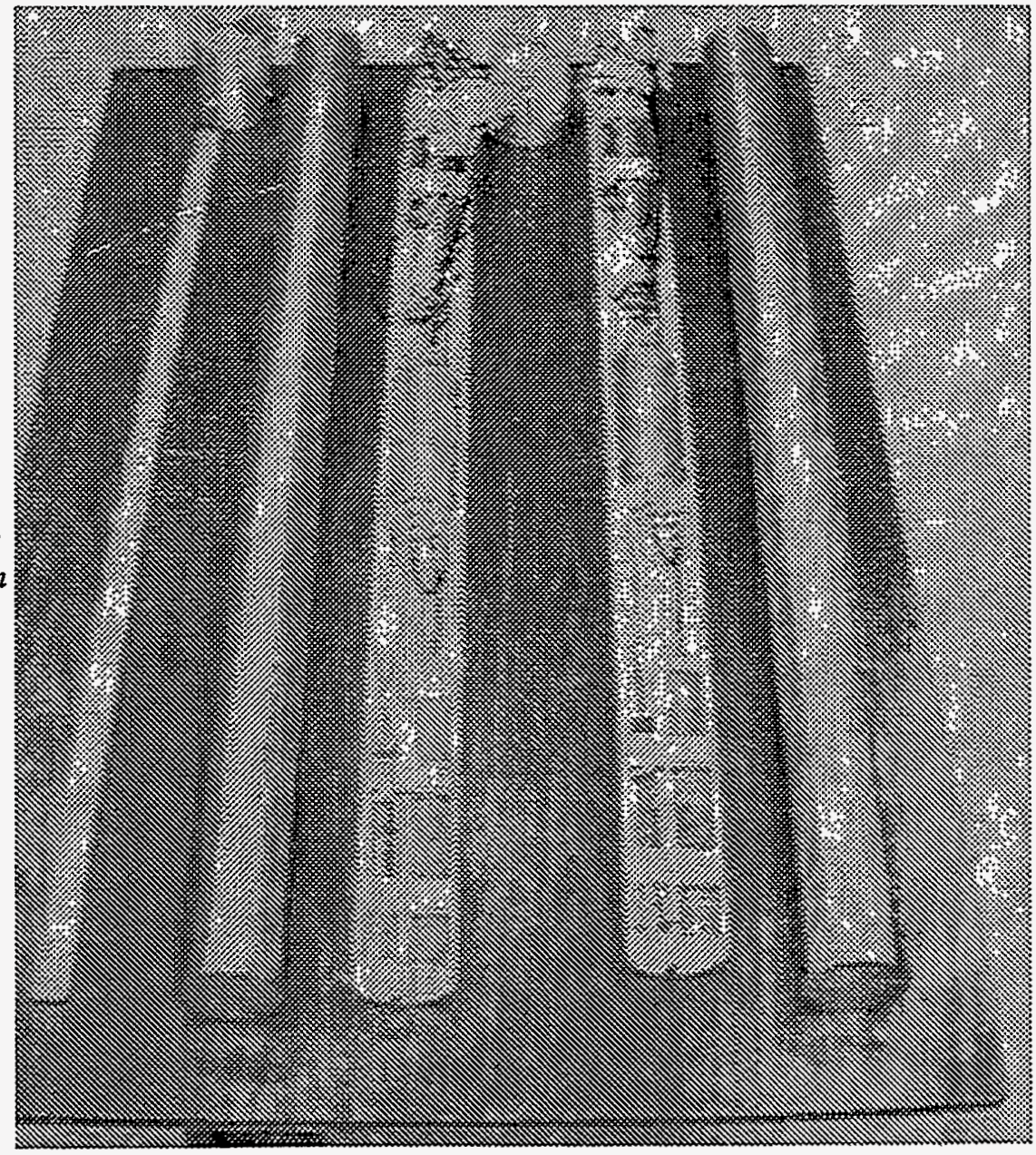




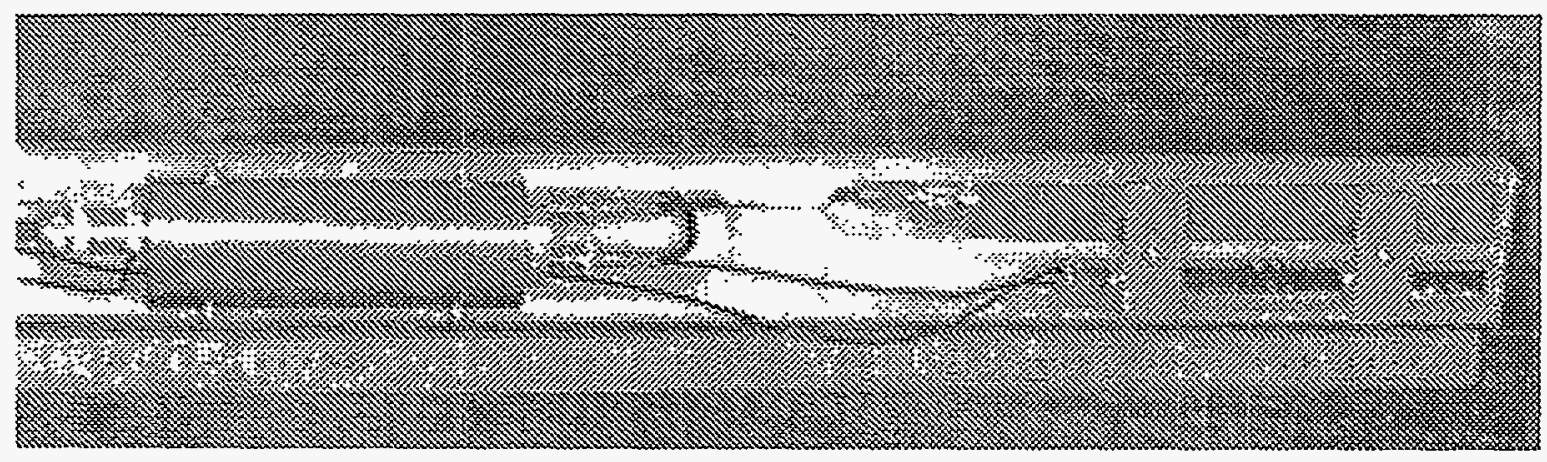

Fig. 3. Closeup photograph of the ${ }^{3} \mathrm{He}$ tube, the IC, and the AMPTEK amplifier covered with the tungsten shield.

PHYSICAL DESCRIPTION (cont.)

ELECTRICAL CONNECTION
The specifications for the ion chambers and ${ }^{3} \mathrm{He}$ tubes are given in Table I.

\begin{tabular}{|l|l|}
\hline \multicolumn{2}{|l|}{ TABLE I. Detector Specifications } \\
\hline Ion chambers (4) & Model LND 52110 \\
\hline Ion chamber bias & $-300 \mathrm{~V}$ \\
\hline${ }^{3} \mathrm{He}$ tubes (4) & RS-P4-0806-106 (MG) \\
\hline${ }^{3} \mathrm{He}$ detector bias & \\
\hline Normal chute & $1740 \mathrm{~V}$ \\
\hline By-pass chute & $1760 \mathrm{~V}$ \\
\hline
\end{tabular}

Both the ion chambers and ${ }^{3} \mathrm{He}$ tubes count gamma rays from the spent fuel as the fuel is pushed through the fuel transfer chute. The detector tubes are positioned $\sim 17-20 \mathrm{~cm}$ from the center line of the fuel transfer chute and parallel to the axis.

The detectors are designed to measure gamma doses in the range of 0.1 to $10^{5} \mathrm{R} / \mathrm{h}$ for contact with the fuel rods. The actual dose at the detector is less because of the $\sim 17-20 \mathrm{~cm}$ separation and the iron and lead shielding.

A diagram of the electronics cabinet is shown in Fig. 4. The electronics include the components listed in Table II. 
21 Oct. 1994

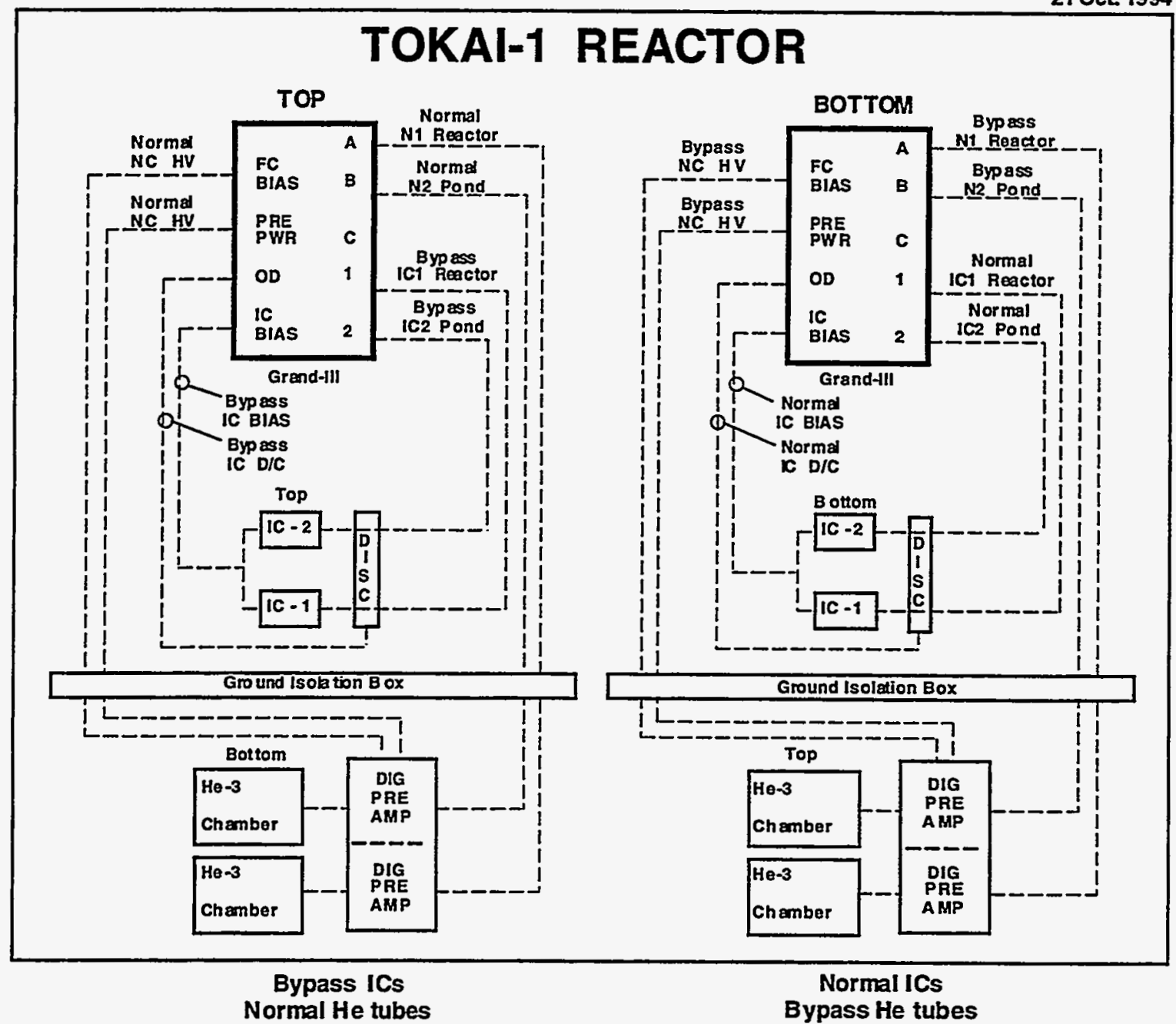

Fig. 4. Diagram of the component wiring in the TOKM electronics cabinet containing two GRANDs, two Kontron computers, and two Bernoullis.

\begin{tabular}{|l|l|}
\hline \multicolumn{2}{|l|}{ TABLE II. TOKM Electronic Components } \\
\hline Kontron Computer & IPL-386SL-25 (SN070790001) \\
Kontron Computer & IPL-386SL-25 (SN046570001) \\
GRAND-3 & Davidson (SNG3-063) \\
GRAND-3 & Davidson (SNG3-064) \\
Bernoulli & Disk drive (SNJX94310195) \\
Bernoulli & Disk drive (SNJXA434007 \\
Bernoulli & Disk drive (SNJUB4340006) \\
Bernoulli & Disk drive (SNJUB4330157) \\
\hline
\end{tabular}


ELECTRICAL CONNECTION (cont.)

${ }^{3}$ He-TUBE HIGHVOLTAGE PLATEAU
ION CHAMBERS
The four ${ }^{3} \mathrm{He}$ tubes are connected to a pair of AMPTEK (Model A111) preamplifiers with dual channel cylindrical construction (fork detector type). ${ }^{2}$ The detector packages are wired to give redundancy for both the GRANDs and the computers. That is, if a GRAND or computer fails, both fuel transfer chutes are still covered by the backup, redundant detector pair. Approximately $35 \mathrm{~m}$ of cable connects the detectors and the electronics cabinet.

The ${ }^{3} \mathrm{He}$ tubes are from Reuter-Stokes with a diameter of $25 \mathrm{~mm}$ and an active length of $152 \mathrm{~mm}$. The fill-pressure of the tubes is four atmospheres of ${ }^{3} \mathrm{He}$ plus a $\mathrm{CO}_{2}$ additive. The aluminum walls of the tube are coated with carbon for radiation resistance.

The high-voltage (hv) plateau for the TOKM ${ }^{3} \mathrm{He}$ tubes is shown in Fig. 5 where the totals counting rate is plotted as a function of the hv bias on the detector tubes. For the current application of the ${ }^{3} \mathrm{He}$ tubes, we are using the detectors to count gamma rays by selecting the hv operating point to be in the gamma pileup region. The correct hv setting was calibrated at the time of installation.

The four ICs are LND Model 52110; they are $19 \mathrm{~mm}$ in diam, $127 \mathrm{~mm}$ long, and contained in a sealed brass tube with a $25-\mathrm{mm}$ outside diameter. The sensitivity range of the IC is from $\sim 0.01$ to $10^{6} \mathrm{R} / \mathrm{h}$.

There is a remote relay disconnect on the IC cable inside the detector pipe. This is to provide an offset reading for the zero-current condition.

The IC has a useful gain range of about eight decades when using the automatic gain-range feature. For the initial application, we are using the manual gain setting to obtain a rapid response for a fast-rising signal. The manual response is limited to a gain range of 3.5 decades. The manual range setting was 16, for a maximum rate of 20500 counts/s and a minimum of 10 counts/s. When the IC signal level drops below 10 counts/s, the data is recorded as zero. The actual background level is $\sim 0.006$ counts/s so the wings of the response peak are lost using the manual setting. For the Tokai- 1 spent fuel transfer in the normal chute, the IC signal was $\sim 5000$ counts/s and $\sim 60$ counts/s in the by-pass chute IC. 
ION CHAMBERS

(cont.)
Future software for the GRAND will implement the full automatic gain range with rapid response.

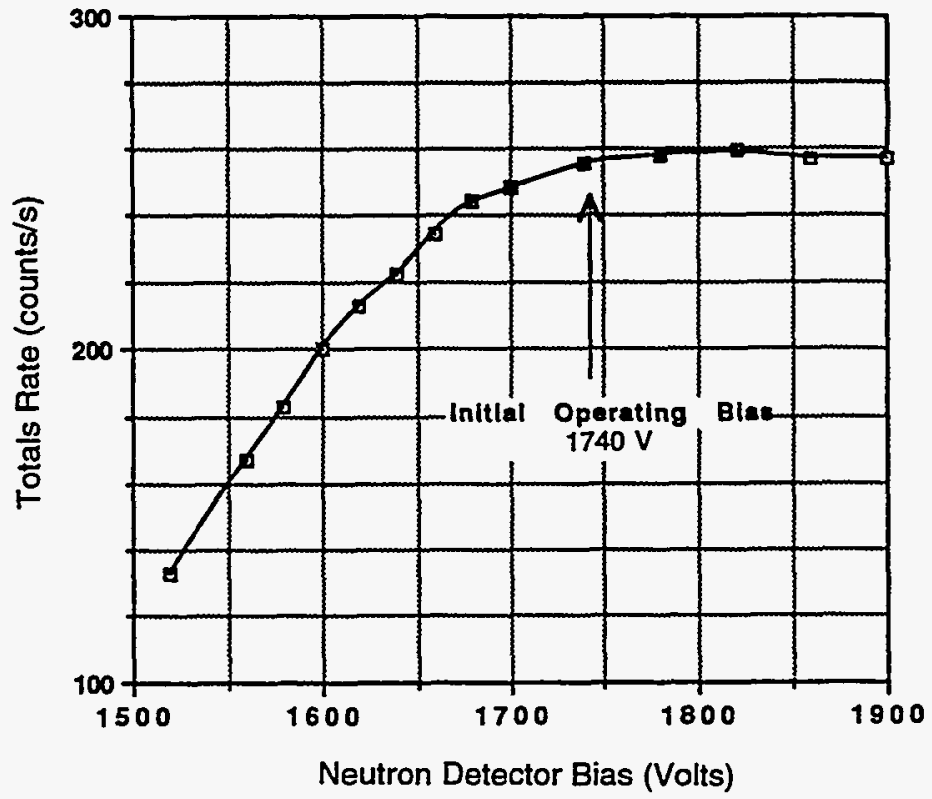

Fig. 5. Detector bias plateau for the ${ }^{3} \mathrm{He}$ tube and AMPTEK amplifier using $50 \mathrm{~m}$ of RG-174 coaxial cable to the GRAND. 
CABLE CONNECTIONS
The eight sensors, the high voltage, and the $+5 \mathrm{~V}$ are connected to the GRANDs using RG-174 coaxial cables with Lemo connectors. Each detector package has eight cable connections as shown in Fig. 6 . Table III gives the Lemo connector type and number.

Two detector assemblies are each connected to redundant GRANDs. One detector assembly is connected to the normal fuel chute; the other detector assembly is connected to the by-pass fuel chute.

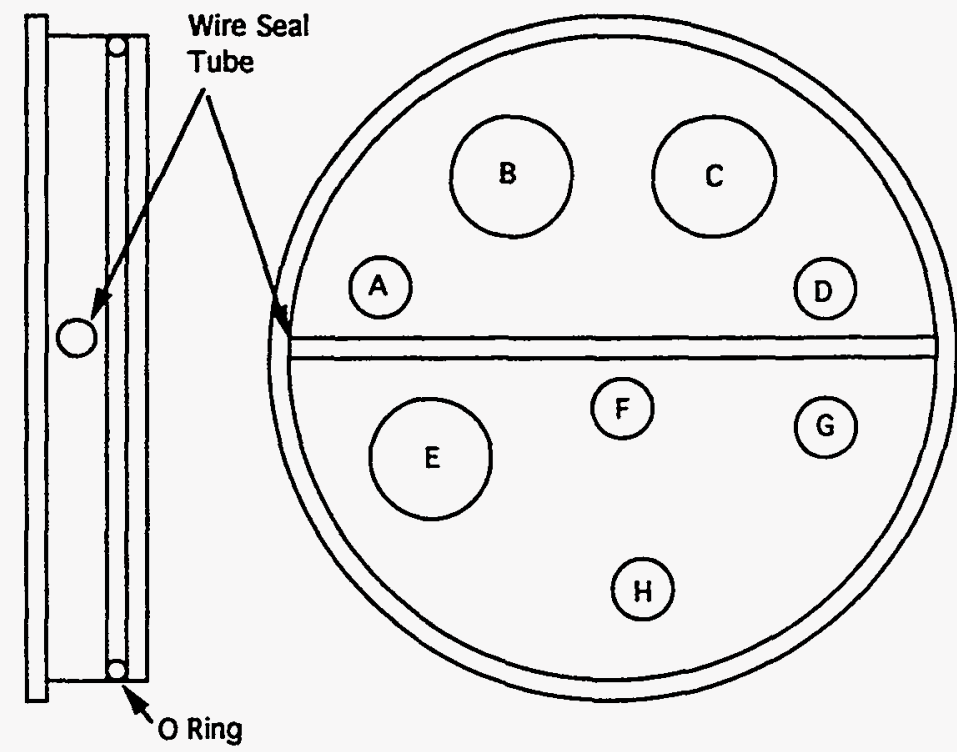
A- IC Bias
E- Neutron Bias
B- IC2 Sig.
F- Neut. Sig. A
C-IC1 Sig.
G- Neut. Sig. B
D- IC Disconnect
H- Neut. $+5 \mathrm{~V}$

Fig. 6. Lemo connector locations on the end of the TOKM detector package.

\begin{tabular}{|c|c|c|}
\hline \multicolumn{3}{|c|}{ TABLE III. Lemo Connector Types } \\
\hline Type & Number & Size \\
\hline FFAOO $250^{\bullet}$ CLAC 27 & 5 & small \\
FFAOE $\cdot 250 \cdot$ CLAC 30 & 3 & large \\
\hline
\end{tabular}


CABLE CONNECTIONS (cont.)

LABELS

GRAND D CONNECTIONS
Eight RG-174 coaxial cables come from each detector assembly. Once the cable bundles come inside the instrumentation rack, they are split into two sub-bundles of four cables each. One sub-bundle is for the ${ }^{3} \mathrm{He}$ detectors, the other is for the ionization chambers. For redundancy, one sub-bundle is routed to one GRAND, the other is routed to the second GRAND.

The GRANDs are labeled GRANDUP and GRANDDN. The ${ }^{3} \mathrm{He}$-tube cables from the normal chute and the ionchamber cables from the by-pass chute connect to GRANDUP. The ${ }^{3} \mathrm{He}$-tube cables from the by-pass chute and the ion-chamber cables from the normal chute connect to GRANDDN.

The general wiring scheme is shown in the Tokai-1 reactorwiring block diagram (see Fig. 4).

As the ${ }^{3} \mathrm{He}$ cables come into a GRAND, they go through a ground isolation box, which puts an inductor between the ground of the GRAND and the grounds of the neutron detector cables that connect to the detector assembly.

The other notable feature shown in the diagram is the ion chamber disconnect labeled DISC.

The two cable bundles are labeled NORMAL and BY-PASS. Labels were installed on the cables in Los Alamos; however, the cables were re-labeled at the time of installation. The new labels are applied to the cables very near to the connector to the GRAND. Each cable has either the word NORMAL or BY-PASS as the first part of its label. This identifies the detector assembly to which it is connected. The labels also contain the word REACTOR or POND. This designates the detector in the detector assembly to which the wire connects. The third part of the designation is the type of detector, IC (for ion chamber), $\mathrm{NC}$, or ${ }^{3} \mathrm{He}$. In the case of bias, LV-power, or disconnects, the word REACTOR or POND will not appear.

Figure 7 shows a diagram of the edge view of the GRAND triple neutron counter and ion chamber personality boards and the connectors on them. Table IV lists the label on the cable, the board to which it attaches, and the connector on the board. 
TRIPLE NEUTRON COUNTER (TNC)

(0)

IC BOARD (IC)

(17) 0 Sig. 0 (19)

Fig. 7. Edge view of the Lemo connector locations in the GRAND.

TABLE IV. Cable Connections and Labels

\begin{tabular}{|l|l|l|}
\hline \multicolumn{1}{|c|}{ Cable Level } & GRAND Board & GRAND Connector \\
\hline Normal N1 Reactor & TNC & A \\
Normal N2 Pond & TNC & B \\
Normal NC HV & TNC & HV \\
Normal NC LV & Side Panel & $9-$ Connector "D" \\
& & \\
Bypass IC1 Reactor & IC & SIG-1 \\
Bypass IC2 Pond & IC & SIG-2 \\
Bypass IC Bias & IC & Bias \\
Bypass IC D/C & IC & Bias \\
\hline
\end{tabular}

GRAND D CONNECTIONS (cont.)

AMPLIFIERS
The coaxial cables (RG-174) that connect the sensors to the GRANDs are approximately $35 \mathrm{~m}$ long. The components were tested with 50-m-long cables before installation.

The four ${ }^{3} \mathrm{He}$ tubes have their AMPTEK A-111 amplifiers inside the sealed detector pipe. ${ }^{2}$ The pipe contains $-300 \mathrm{~cm}^{3}$ of desiccant. The cable between the tubes and the AMPTEK is $20-30 \mathrm{~cm}$ long. The gain in the AMPTEK amplifiers was preset prior to installation using the same criteria as for the HLNC-II. ${ }^{3}$ The ${ }^{3} \mathrm{He}$ detector bias in the GRAND was adjusted at the time of calibration to provide the desired sensitivity level. The hv was set at $1740 \mathrm{~V}$ for the normal chute and $1760 \mathrm{~V}$ for the by-pass chute so that the system was sensitive to fuel pushes in both the adjacent and opposite chutes. 
PERFORMANCE

CHARACTERISTICS

${ }^{3}$ He TUBE TESTS
Prior to installation, the performance of the ${ }^{3} \mathrm{He}$ tubes and the ICs was measured at Los Alamos using a ${ }^{226} \mathrm{Ra}$ gammaray source and $\mathrm{a}^{252} \mathrm{Cf}$ neutron source. The cable between the detector package and the GRAND was $50 \mathrm{~m}$ long to check for possible attenuation of the signals.

$\mathrm{A}^{252} \mathrm{Cf}$ neutron source was used to measure the hv plateau shown in Fig. 5. The normal operating hv for neutron counting would be about $1700 \mathrm{~V}$; however, we are using the ${ }^{3} \mathrm{He}$ tubes to monitor neutrons for times between fuel transfers and gamma rays during the fuel transfers. Thus, we needed to set the hv at $\sim 1740$ to be sensitive to the gamma-ray dose from the spent-fuel rods.

We performed measurements in the LANL hot cell using a ${ }^{226} \mathrm{Ra}$ gamma-ray source. The design-basis fuel rods range from 1000 to $50000 \mathrm{R} / \mathrm{h}$ at contact. The ${ }^{226} \mathrm{Ra}$ source has a dose level of $\sim 1500 \mathrm{R} / \mathrm{h}$ on contact so it provides a reasonable simulation of the low-intensity spent-fuel rods. The normal detector-to-fuel-rod separation is $\sim 20 \mathrm{~cm}$ so we positioned the ${ }^{222} \mathrm{Ra}$ source at $20 \mathrm{~cm}$ from the center line of the detector package. Figure 8 shows the gamma-ray pileup data rate as a function of the ${ }^{3} \mathrm{He}$ detector's bias. The pileup was observable at $1720 \mathrm{~V}$ and we set the initial operating hv at $1740 \mathrm{~V}$. The ${ }^{3} \mathrm{He}$ detector counting rate saturates at $\sim 1.5 \mathrm{x}$ $10^{5}$ counts/s for the $50000-\mathrm{R} / \mathrm{h}$ fuel rods.

The two ${ }^{3} \mathrm{He}$ tubes are separated by $-75 \mathrm{~cm}$ in the detector package (see Fig. 1) to provide data on the direction of motion and speed of the spent-fuel-rod transfers. Measurements using a neutron source were performed in the LANL hot cell to determine the spatial resolution of the pair of ${ }^{3} \mathrm{He}$ tubes. Figure 9 shows the measured response profiles for the tubes when a neutron source was moved on an axis that was separated by $20 \mathrm{~cm}$ from the center line of the detector package. The two detectors clearly show the direction of motion of the source by the rise time of the two peaks.

For measuring the relative gamma-ray dose, the ICs have an advantage over the ${ }^{3} \mathrm{He}$ tubes in that the IC response is proportional to the gamma source strength, whereas, the response of the ${ }^{3} \mathrm{He}$ tubes is nonlinear and saturates for high dose levels. Figure 10 shows the IC response as a function of distance from the $1500 \mathrm{R} / \mathrm{h}^{226} \mathrm{Ra}$ source at LANL. At the 


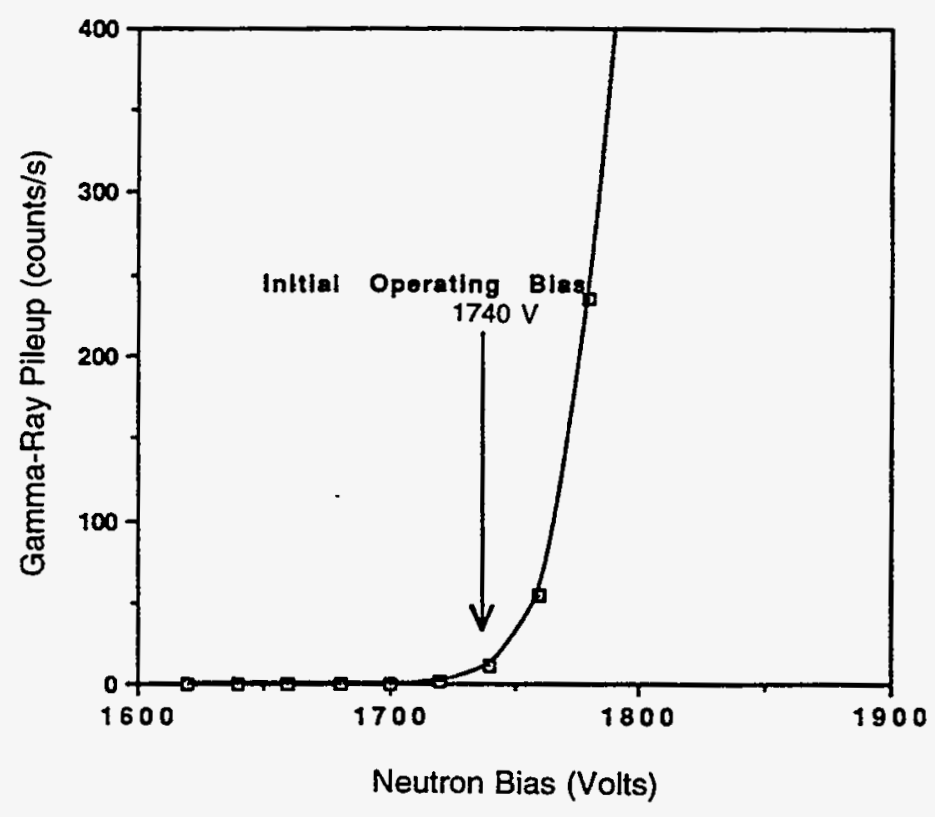

Fig. 8. The ${ }^{3} \mathrm{He}$ detector response to gammaray pileup as a function of detector hv bias for a $1500 \mathrm{R} / \mathrm{h}^{226} \mathrm{Ra}$ gamma source located $20 \mathrm{~cm}$ from the detector.

Fig. 9. Neutron detector's spatial response for a point source of neutrons being moved along an axis $20 \mathrm{~cm}$ from and parallel to the TOKM detector axis.

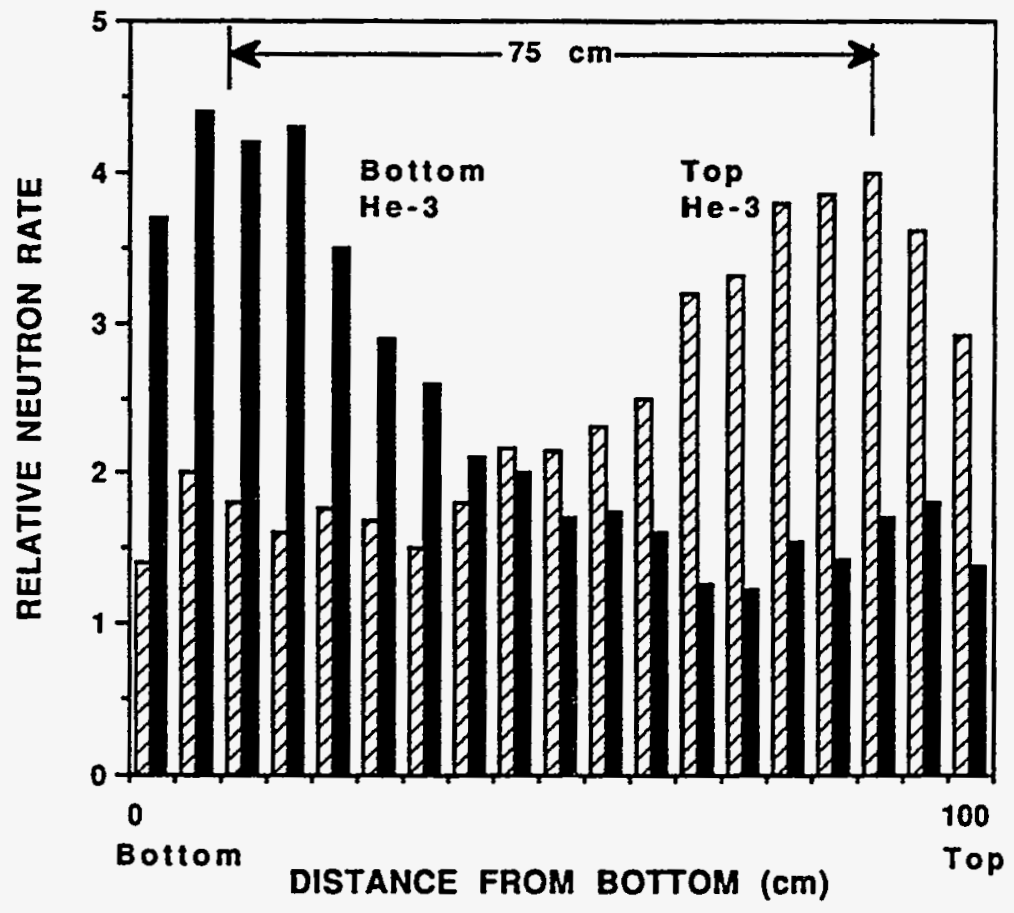




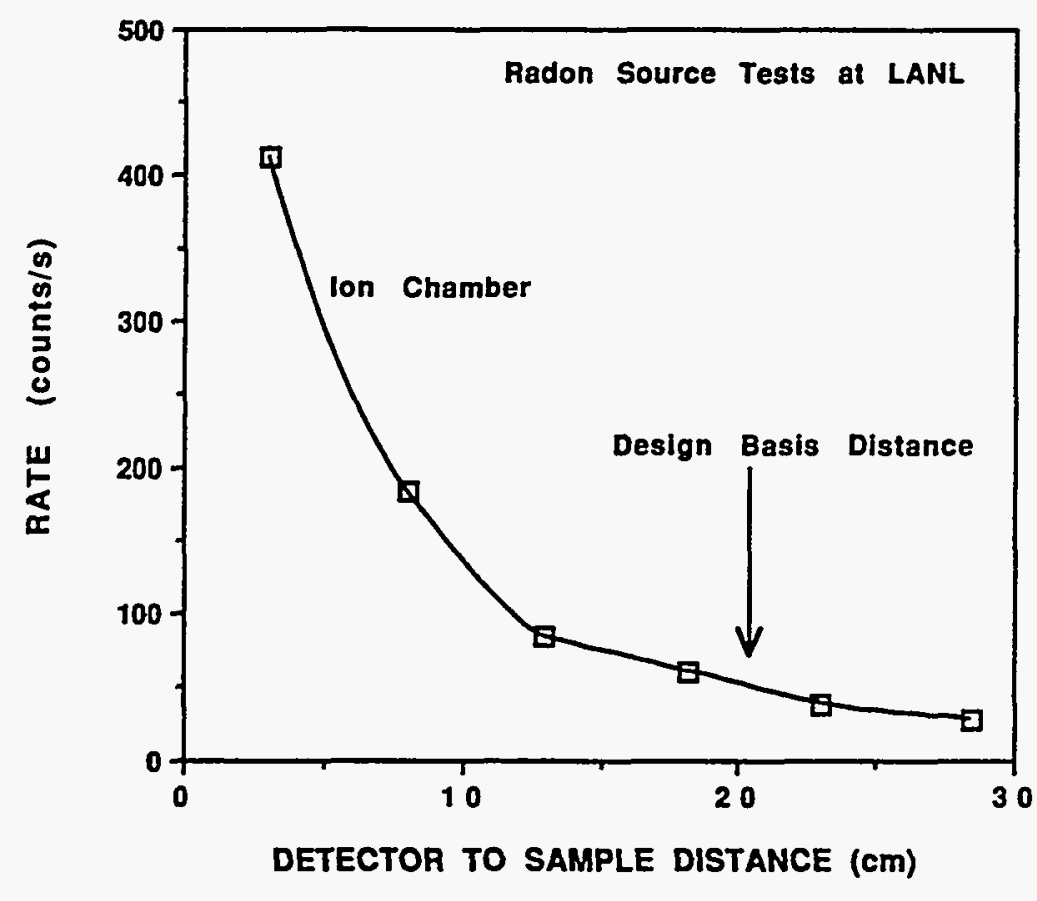

Fig. 10. The IC gamma response vs distance from a $1500 \mathrm{R} / \mathrm{h}$ contact gamma-ray source.

IC TESTS (cont.)

\section{CALIBRATION}

design-basis distance of $20 \mathrm{~cm}$, the IC sensitivity is several orders of magnitude above the background noise level. The two ICs in each detector package are used to provide redundant data on the direction of motion and speed of the fuel rod transfers. Figure 11 shows the response profiles for the two ICs demonstrating that the spatial resolution is adequate to show direction of motion at the $20-\mathrm{cm}$ detectorto-sample spacing.

At the time of installation, the ICs and ${ }^{3} \mathrm{He}$ tubes were calibrated using fuel transfers through both the normal and the by-pass chutes. A typical fuel transfer includes a set of eight fuel rods that represent a vertical channel in the Tokai-1 reactor core. The first rod transferred originates from the bottom of the core and the eighth rod is from the top of the core. Table $\mathrm{V}$ lists the relative burnup for two sets of eight fuel rods that were used for calibration.

The transfer takes the rods from the reactor location past the TOKM detector package to the storage pool area.

In addition to the eight rods that were transferred through the normal chute, another eight rods were moved through the by-pass chute. The data demonstrated that the transfers in both chutes could be clearly detected in either chute. 


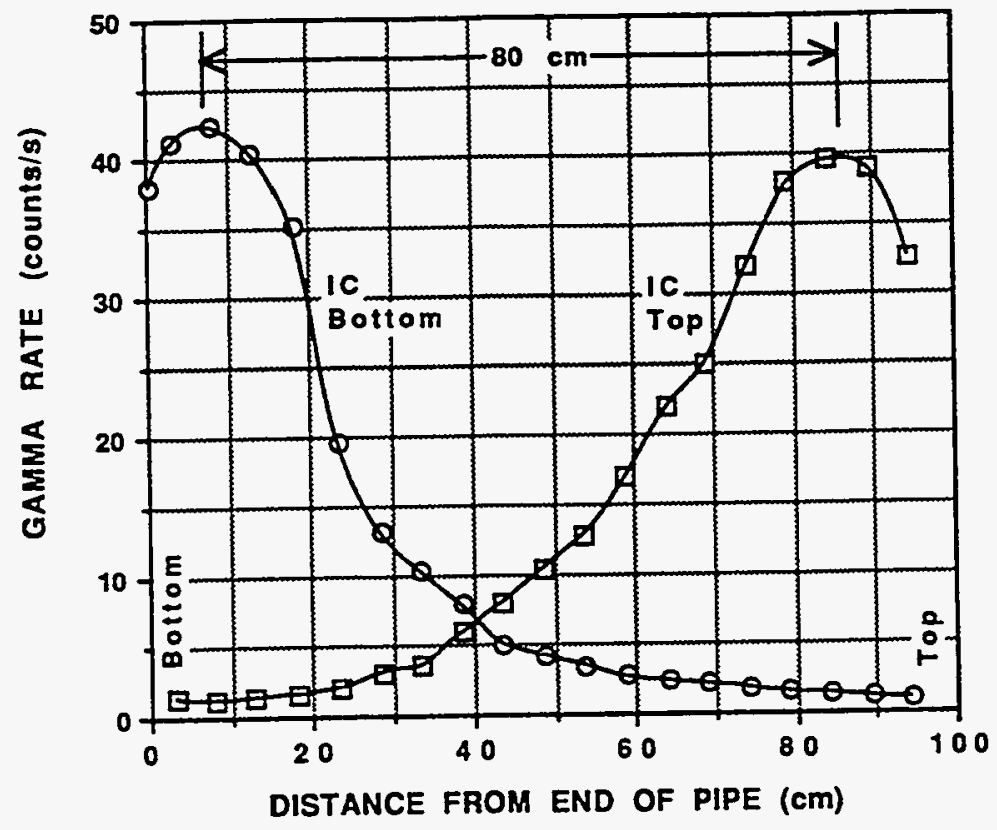

Fig. 11. The IC detector's spatial response for a point source of gammas being moved along an axis $20 \mathrm{~cm}$ from and parallel to the TOKM detector axis.

\begin{tabular}{|c|c|c|}
\hline \multicolumn{2}{|c|}{ TABLE V. Calibration Fuel Rods } \\
\hline $\begin{array}{c}\text { Fuel Rod } \\
\text { Position }\end{array}$ & $\begin{array}{c}\text { Calib. Set 1 } \\
\text { Burnup } \\
\text { (MWd/tU) }\end{array}$ & $\begin{array}{c}\text { Calib. Set 2 } \\
\text { Burnup } \\
\text { (MWd/tU) }\end{array}$ \\
\hline 1 & 2500 & 2100 \\
2 & 3890 & 3260 \\
3 & 4500 & 3770 \\
4 & 4620 & 3870 \\
5 & 4340 & 3630 \\
6 & 3670 & 3070 \\
7 & 2640 & 2220 \\
8 & 1430 & 1200 \\
\hline
\end{tabular}

CALIBRATION (cont.)
For test purposes, one rod was moved backward through the normal chute to evaluate the capability of the detector system to measure the direction of motion. 
NORMAL CHUTE RESULTS

BY-PASS CHUTE RESULTS

REVERSE DIRECTION TRANSFER
Figure 12 shows four graphs of the two ICs and two ${ }^{3} \mathrm{He}$ tubes for the transfers of eight fuel rods through the normal chute.

The data was collected with a 2-s time frequency and the transfer time offset was $\sim 4 \mathrm{~s}$ between the front (reactor side) detectors and the back (pond side) detectors. The time separation between each fuel rod transfer was about $10 \mathrm{~min}$. The relative intensity of eight rods shows the reactor power profile over the height of the reactor core. The signal levels are about six orders of magnitude above the background levels and the total transfer time with a measurable signal is about $34 \mathrm{~s}$. The ${ }^{3} \mathrm{He}$-tube response covers the full range of seven orders of magnitude in the signal so that on the log display the patterns of the approach and departure of the fuel rod are distinct. The IC response is in the manual range from 10 to 20500 counts/s, so the low-level wings of the peak are lost. Future GRAND software versions will allow the automatic gain-range feature so that the full response range will be collected.

The direction of motion also can be detected by the shape of the ${ }^{3} \mathrm{He}$ peaks. Figure 13 shows the log display of the ${ }^{3} \mathrm{He}$ peaks for three fuel rod transfers. The shoulder on the right side of the peaks is caused by the long transfer distance in the view of the detector as the rod is moved towards the pool area.

For fuel-rod transfers through the by-pass chute, the results are identical to the normal chute results shown in Fig. 12. However, the by-pass chute detectors also give definitive results on fuel transfer through the normal chute. Figure 14 shows the responses in the four by-pass detectors for eight fuel rod transfers through the normal chute. In this case the signal-to-background ratio is $\sim 10^{3}$, which is three orders of magnitude below the normal chute detectors. The separation distance between the normal and by-pass chutes is $\sim 5 \mathrm{~m}$. Only a few fuel passes per year are planned for the by-pass chute so this detector package will primarily provide redundancy data for the normal chute detectors.

To test the ability of the TOKM system to distinguish between a normal transfer and a reverse-direction transfer, we transferred a fuel rod through the normal chute and then returned it to the reactor, followed by a repeat transfer to the 

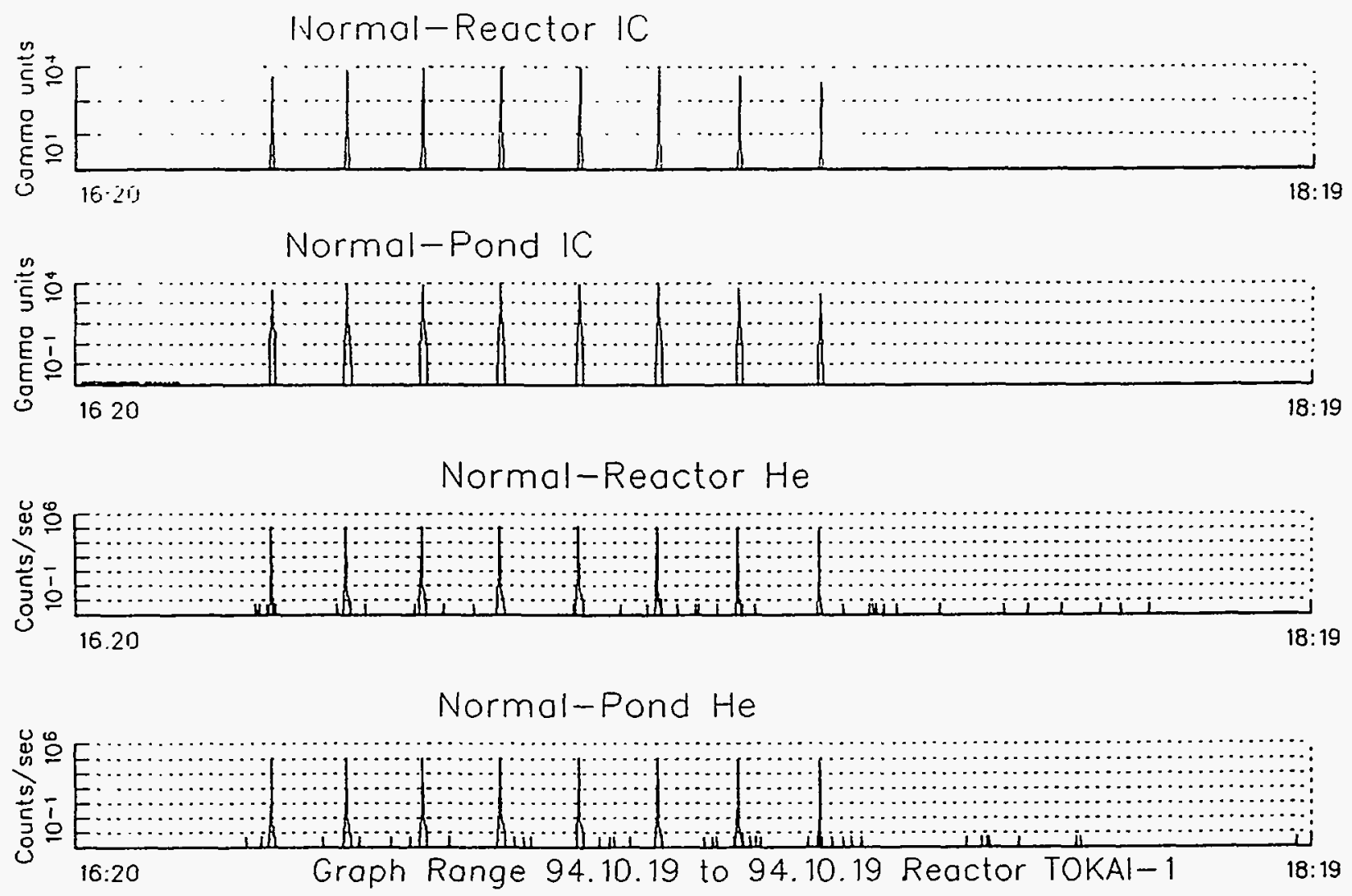

Fig. I2. Calibration response for eight fuel rods transferred through the normal chute. The top curve is the response of the IC nearest to the reactor; the second curve is the response of the IC nearest to the storage pond. The bottom two curves are similar data for the corresponding ${ }^{3} \mathrm{He}$ tubes. 

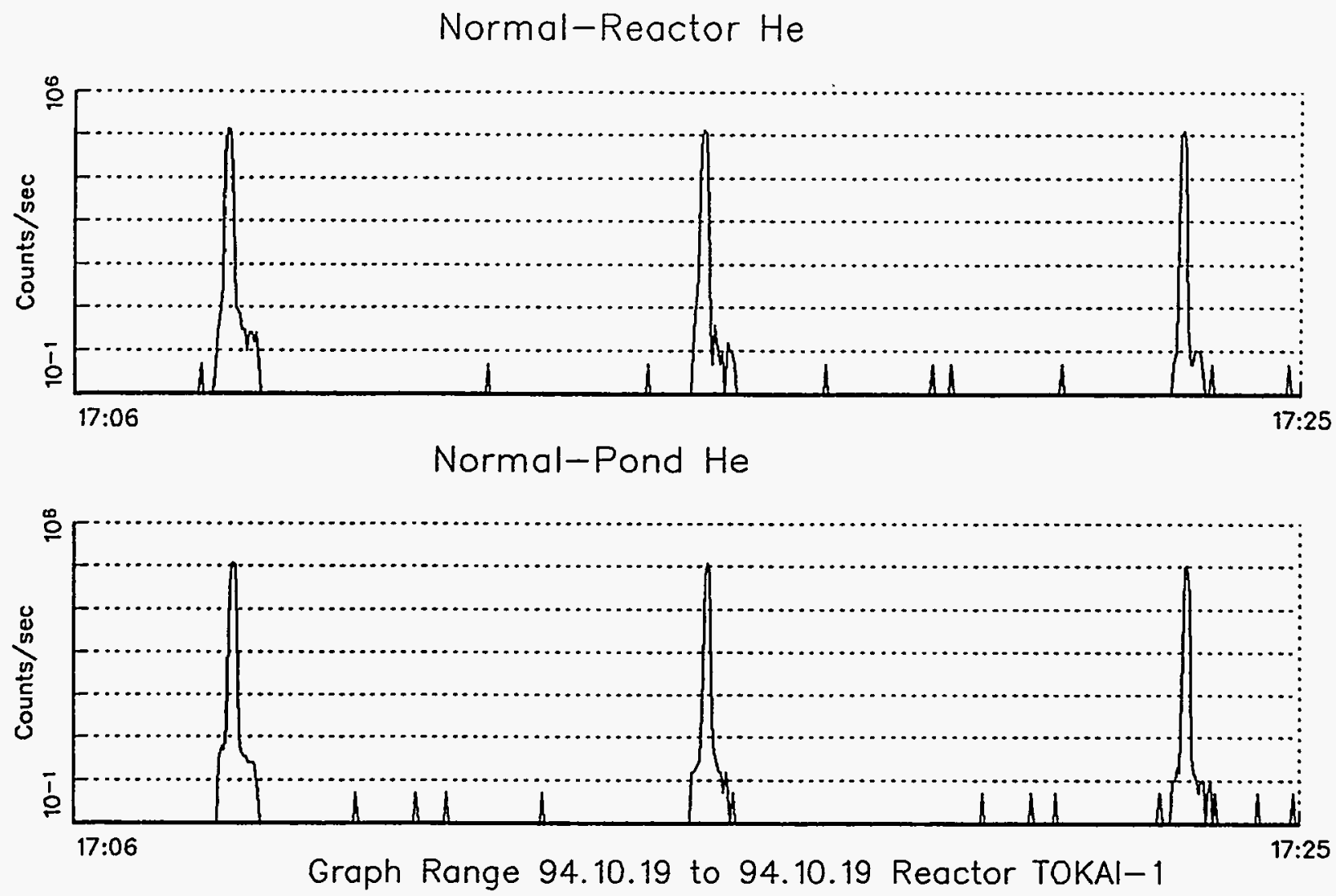

Fig. 13. Calibration response from the two ${ }^{3} \mathrm{He}$ tubes in the normal chute showing the direction of motion from the shape of the peak with the slow decline towards the pond side. The small spikes are single neutron counts in the background. 

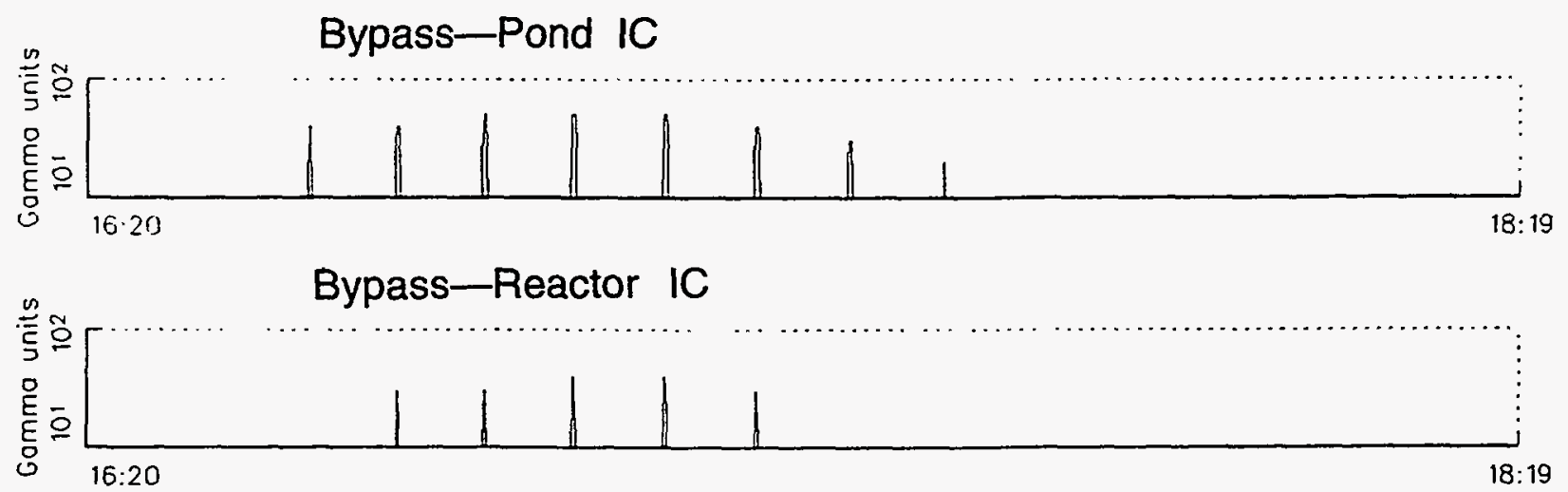

\section{Bypass-Pond He}

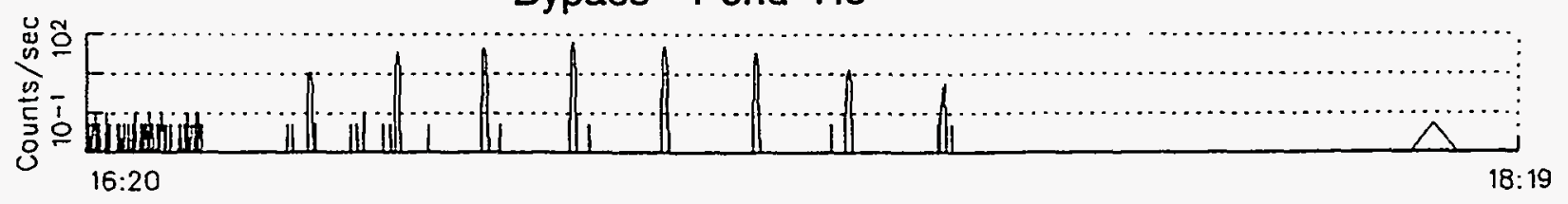

Bypass-Reactor $\mathrm{He}$

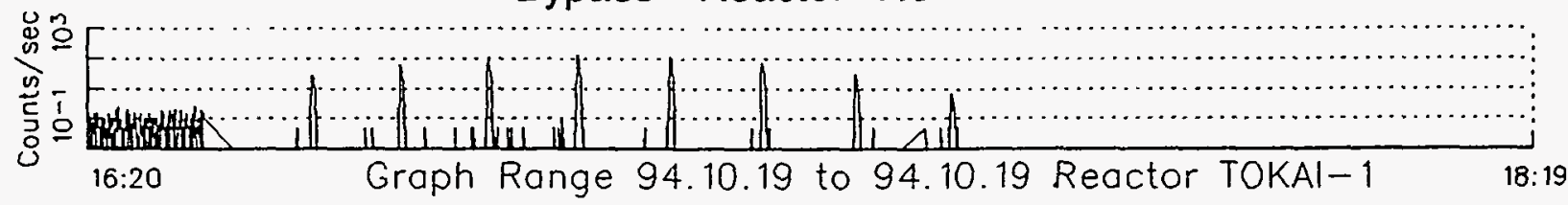

Events for $94.10 .19=16$

Fig. 14. The ${ }^{3}$ He tube responses in the by-pass chute detectors from fuel transfers in the normal chute. The IC is on manual scale causing the two weakest data peaks to drop below the threshold (auto-scaling will correct this). 


\section{REVERSE DIRECTION TRANSFER (cont.)}

pool. This resulted in the three transfer peaks shown in Fig. 15 with the first and third peaks in the forward direction and the second peak in the reverse direction. The direction of transfer can be determined by the $-4-s$ time shift between the front and back detector pairs and also by the shape of the peaks for the ${ }^{3} \mathrm{He}$ detectors.

For one of the calibration rod transfers, the release mechanism was stuck at the pool position so the rod remained in the transfer tube longer than normal. Figure 16 shows the data pattern from the four detectors in the normal chute, and we see the elevated count rate with the exposed rod several meters distant from the detector location. The bypass chute was also sensitive enough to record this event.
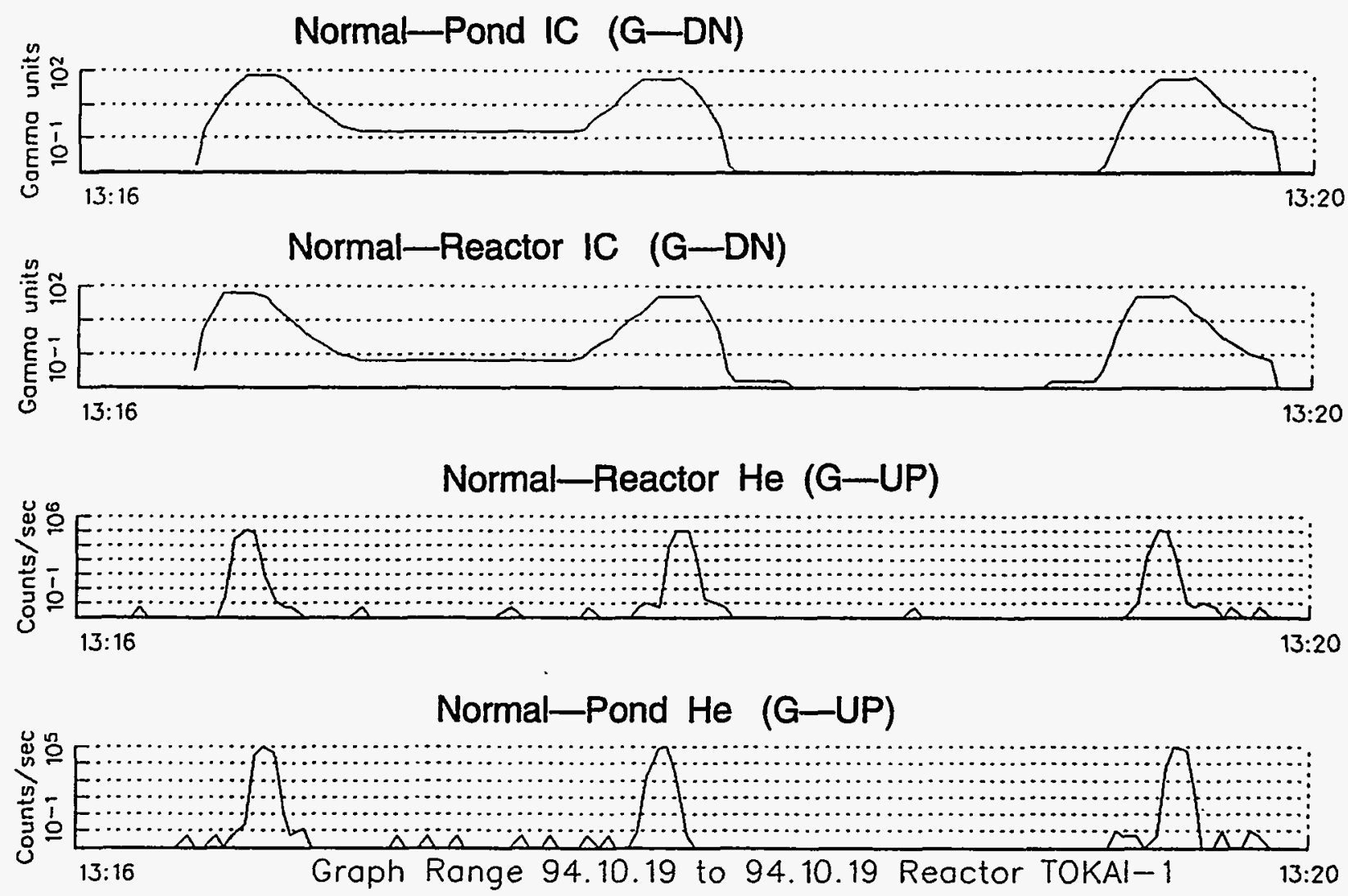

Fig. 15. The response pattern from the four detectors in the normal chute for a fuel transfer without release in the pond followed by a return of the rod to the reactor side and then a return of the rod to the pool area. 

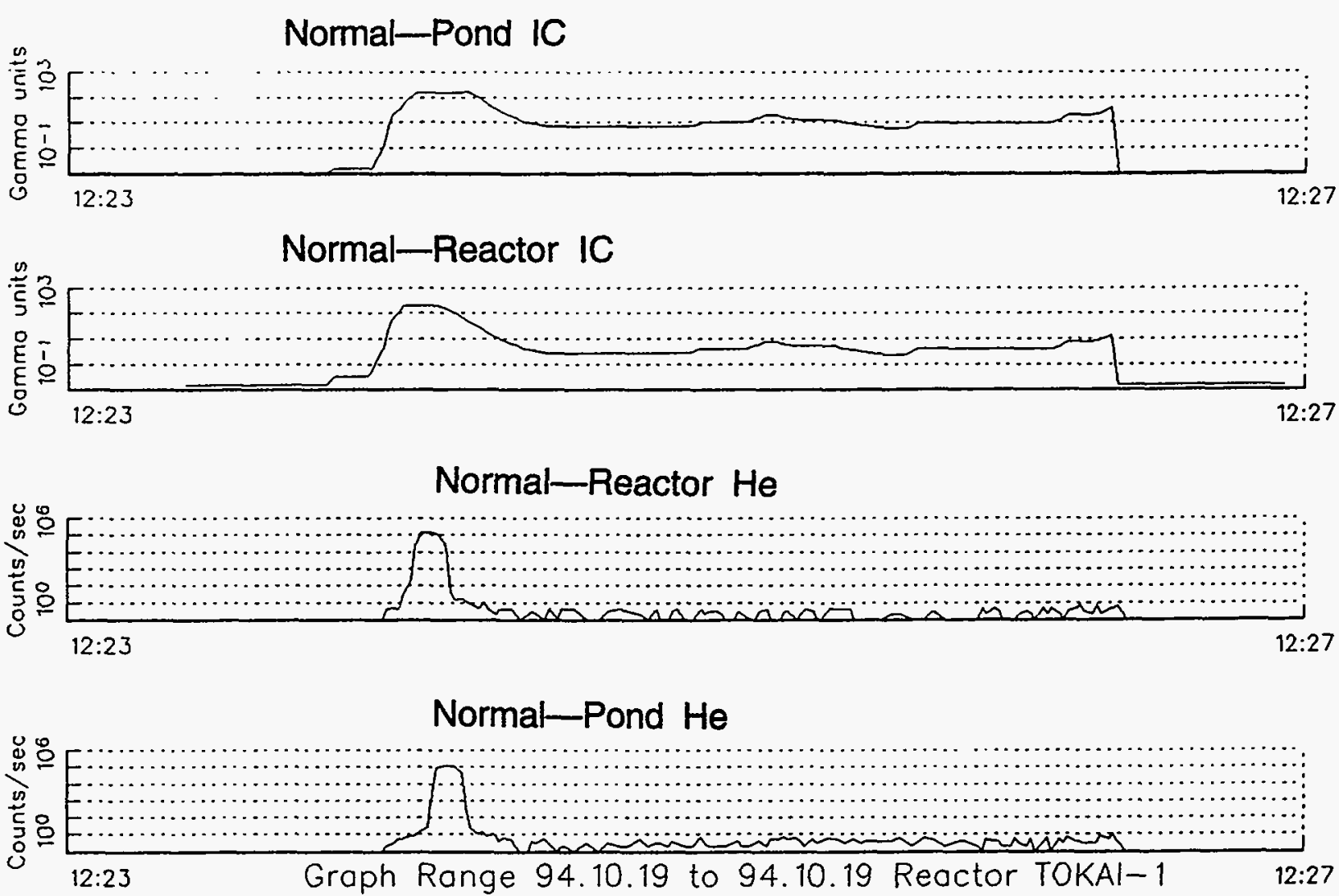

Fig. 16. The response pattern from the four detectors for a normal chute transfer rod that was stuck for about two minutes at the pool release position. 
RADIATION SAFETY

ELECTRICAL CABINET
The primary radiation safety problem is experienced during the initial installation of the TOKM detector package at the fuel transfer chutes. Full anticontamination suits with external breathing-air supply must be worn. The facility operator performed this task with participation by an IAEA inspector and a Japan Nuclear Safety Bureau (JNSB) inspector for authentication and the application of seals. This high-radiation area cannot be accessed when the reactor is in operation, and this entire area is under IAEA seal.

The two detector packages have four-fold redundancy to avoid the necessity of having to reeenter this high-dose area for maintenance or repair. The detector packages are designed to last for the life of the reactor without maintenance or service. In case of the failure of a sensor, the redundant sensors would be used and no repair would be attempted in the hot areas.

Should it become necessary to re-enter the detector fuelchute area, special work procedures and training will be provided by the facility operator. This contaminated area is under IAEA seal and the inspector and operator are locked out of this area except when special access is provided by the Tokai- 1 operator and the seals are removed.

The GRAND and computers are located in an installed IAEA cabinet with a ground to the building ground. All electronic components are modular commercial items and satisfy standard UL (or equivalent) requirements. If it is necessary to repair the commercial components in the electrical cabinet, the inspector will remove the module and replace it with an identical module. The failed component will be returned to the IAEA's field office or headquarters for repair.

The electrical power for the TOKM will be a constantvoltage-constant-frequency (CVCF) power supply that will be provided by the facility operator. The supply will give $100-\mathrm{V} / 50-\mathrm{Hz}$ electrical power that will not be interrupted in the case of line-power failure. This power supply will be grounded to the building electrical ground.

The UL-approved (or equivalent) power cord between the electronics cabinet and the CVCF supply will be grounded to the electrical supply. 
ELECTRICAL CABINET
(cont.)

\section{REDUNDANCY}


REDUNDANCY (cont.)
This high level of redundancy in the sensors is important to avoid maintenance in the contaminated area of the sensors.

The redundancy is only two-fold for the two GRANDs and the two computers; however, they are in the cabinet where modular replacements are possible.

The performance of the TOKM system can be monitored by checking the consistency of the eight sensors. Each sensor should provide the same information on the number of transfers and the direction of motion. 


\section{REFERENCES}

1. J. E. Swansen, "Deadtime Reduction in Thermal Neutron Coincidence Counter," Los Alamos National Laboratory report LA-9936-MS (March 1984).

2. P. M. Rinard and G. E. Bosler, "Safeguarding LWR Spent Fuel with the Fork Detector," Los Alamos National Laboratory report LA-11096-MS (March 1988).

3. H. O. Menlove and J. E. Swansen, "A High-Performance Neutron Time-Correlation Counter," Nucl. Technol. 71, 497-505 (November 1985). 